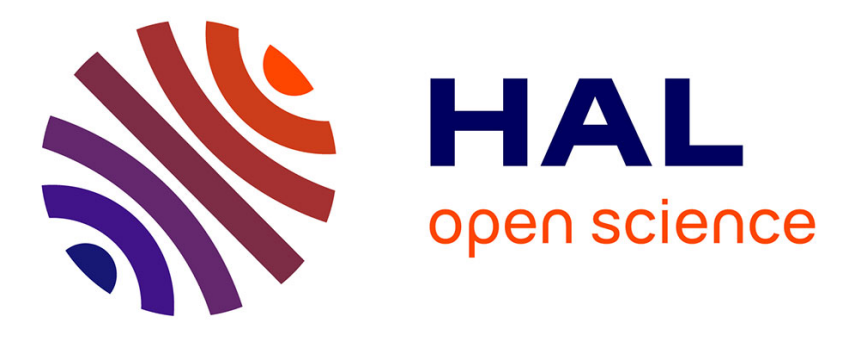

\title{
Modelling of gasmetal arc welding taking into account metal vapour
}

M Schnick, U Fuessel, M Hertel, M Haessler, A Spille-Kohoff, a B Murphy

\section{To cite this version:}

M Schnick, U Fuessel, M Hertel, M Haessler, A Spille-Kohoff, et al.. Modelling of gasmetal arc welding taking into account metal vapour. Journal of Physics D: Applied Physics, 2010, 43 (43), pp.434008. 10.1088/0022-3727/43/43/434008 . hal-00569738

\section{HAL Id: hal-00569738 \\ https://hal.science/hal-00569738}

Submitted on 25 Feb 2011

HAL is a multi-disciplinary open access archive for the deposit and dissemination of scientific research documents, whether they are published or not. The documents may come from teaching and research institutions in France or abroad, or from public or private research centers.
L'archive ouverte pluridisciplinaire HAL, est destinée au dépôt et à la diffusion de documents scientifiques de niveau recherche, publiés ou non, émanant des établissements d'enseignement et de recherche français ou étrangers, des laboratoires publics ou privés. 


\title{
MODELLING OF GAS-METAL ARC WELDING TAKING INTO ACCOUNT METAL VAPOUR
}

\author{
M. SCHNICK*, U. FUESSEL*, M. HERTEL*, M. HAESSLER*, A. SPILLE-KOHOFF**, \\ A. B. MURPHY*** \\ * Technische Universität Dresden, Germany \\ ** CFX Berlin Software GmbH, Germany \\ *** CSIRO Materials Science and Engineering, PO Box 218, Lindfield NSW 2070, Australia
}

\begin{abstract}
The most advanced numerical models of gas-metal arc welding (GMAW) neglect vaporization of metal, and assume an argon atmosphere for the arc region, as is also common practice for models of gas-tungsten arc welding (GTAW). These models predict temperatures above $20000 \mathrm{~K}$ and a temperature distribution similar to GTAW arcs. However, spectroscopic temperature measurements in GMAW arcs demonstrate much lower arc temperatures. In contrast to measurements of GTAW arcs, they have shown the presence of a central local minimum of the radial temperature distribution.
\end{abstract}

This paper presents a GMAW model that takes into account metal vapour and that is able to predict the local central minimum in the radial distributions of temperature and electric current density. The influence of different values for the net radiative emission coefficient of iron vapour, which vary by up to a factor of hundred, is examined. It is shown that these net emission coefficients cause differences in the magnitudes, but not in the overall trends, of the radial distribution of temperature and current density. Further, the influence of the metal vaporization rate is investigated. We present evidence that, for higher vaporization rates, the central flow velocity inside the arc is decreased and can even change direction so that it is directed from the workpiece towards the wire, although the outer plasma flow is still directed towards the workpiece. In support of this thesis, we have attempted to reproduce the measurements of Zielinska et al for spray-transfer mode GMAW numerically, and have obtained reasonable agreement.

\section{INTRODUCTION}

Gas-metal arc welding (GMAW), also known as metal inert-gas (MIG) and metal active-gas (MAG) welding, is a long-established process that is used for joining metals. The arc is established between the workpiece and a continuously-fed wire anode. The plasma flow and the arc attachment at the wire have an important influence on the droplet formation and the heat transfer. Conversely, the droplet geometry, surface temperatures and vaporization affect the fluid flow and the heat transfer inside the arc. A comprehensive understanding of the welding process and the physical effects involved are necessary to reduce the number of experimental parameter studies required and to advance the development of welding techniques and equipment. By developing reliable numerical simulations of arc welding, we can better understand of the complex cause-and-effect-chains in involved in the process; further, the simulations can be applied as an engineering tool for better process design and visualization.

The GMAW models that have been developed previously differ in the effects being studied and the corresponding models [1]. The main focus of most models has been the prediction of droplet formation. State-of-the-art models include volume-of-fluid (VoF) multiphase modelling of a free surface [2]. For the calculation of the electric current density, resistive heating and pinch force in the droplet, VoF-based models either use heat and electric current flux boundary conditions [3] or are combined with an arc model $[4,5,6]$ that has been developed and tested for gas-tungsten arc welding (GTAW) arcs. The arc models are based on magnetohydrodynamics (MHD) and assume a single-component fluid, usually argon, in a state of a local thermodynamic equilibrium (LTE). In $[4,5,6]$, the arc attachment at the wire and the workpiece is simplified by using an increased mesh size. Spille-Kohoff [7] neglected the droplet formation but used the unified sheath model developed by Lowke et al [8] and Sansonnens et al [9] for modelling the transient behaviour of a GMAW process in argon. All of these arc models predict arc temperature distributions and plasma flows similar to those that have been measured for GTAW arcs. 
Peak temperatures of 20000 to $23000 \mathrm{~K}$ were calculated directly below the wire. The arc temperature at the centre line of the arc was always higher than $16000 \mathrm{~K}$, except in the near-electrode regions.

However, spectroscopic measurements of the plasma temperature in GMAW arcs contradict the predicted arc temperatures. The unpublished papers of Metzke and Schöpp [10] and Goecke [11] contain optical emission spectroscopy (OES) analyses of pulsed GMAW processes using copper and aluminium wires. The results indicated high local concentrations of metal vapour during the pulse. The metal vapour was not evenly distributed; a high concentration occurred in the arc core, while argon dominated in the fringes of the arc. The measured radial temperature distribution had a maximum at $13000 \mathrm{~K}$, which is located at the transition region between the regions in which metal vapour and argon dominated. In contrast to GTAW arcs, a central temperature minimum of $8000 \mathrm{~K}$ was observed. The recent measurements of Zielinska et al [12,13] were performed for GMAW with a mild steel wire in spray transfer mode, and confirmed the results of $[10,11]$. The measured temperatures were compared with numerical predictions of [4], and the large discrepancies were traced back to the influence of the metal vapour, which was neglected in the model.

The influence of the metal vapour on the arc behaviour has been analysed numerically mainly for GMAW [14]. Tashiro et al [15] modelled a GTAW arc in helium, assuming a uniform concentration of metal vapour. The metal vapour was found to lead to higher temperatures and greater arc constriction. The GTAW models of Yamamoto et al [16,17] and Lago et al [18] included vaporization at the workpiece surface, and considered the mixing of metal vapour and argon. However, the simple treatments of diffusion used are likely to be inaccurate [19], and did not allow the effects of subsequent demixing $[20,21]$ to be taken into account.

In contrast to GTAW, the metal vapour in GMAW results mainly from evaporation at the wire and droplet surfaces. To take this into account, we developed an MHD model of GMAW assuming a defined distribution of metal vapour at the lower side of the wire, which then streams into the arc [22]. We used a vaporization rate of $1 \%$ of the wire feed rate, and presented results for arc currents between $100 \mathrm{~A}$ and $400 \mathrm{~A}$. The workpiece was assumed to be flat, and the transient behaviour of droplet formation was neglected. A sophisticated model of diffusion and demixing was incorporated to ensure that the metal vapour transport was accurately treated. The calculations predicted a central temperature minimum, in accordance with the measurements described above.

As well as giving a more detailed description of the model than was possible in the earlier short communication, the current paper presents three important extensions. First, we investigate the influence of the net emission coefficient on the predictions of the model. This is a significant question, since published datasets of the net emission coefficient of iron vapour differ at least an order of magnitude. Second, we previously presented results for only one metal vaporization rate. This rate was deliberately chosen to be on the low side of those estimated in the literature so as to demonstrate that large changes could occur for relatively low metal vapour concentrations. However, higher rates are estimated for the GMAW spray transfer mode, and we find that increasing the vaporization rate has a major effect on the arc properties. Finally, we present a thorough comparison of our results with both the high-speed video images, and the spectroscopic measurements, that were presented by Zielinska et al [12].

We begin the paper with an extended description of the model in section 2, and present some representative results in section 3. In sections 4 and 5, we present our calculations of the influence of the net emission coefficient for iron vapour and the influence of the vaporization rate, respectively. The comparison of our calculations with the measurements of Zielinska et al, and a discussion of the ramifications, are presented in section 6 . Our conclusions are given in section 7 .

\section{ARC MODEL}

The commercial simulation software ANSYS CFX is used for an axisymmetric steady-state model of an electric arc. We use the standard equations of computational fluid dynamics (conservation of mass, momentum and energy) and add the electromagnetic and radiative phenomena that occur in thermal plasmas [20]. The changes required are the addition of ohmic heating and radiative loss terms to the energy equation and a magnetic pinch term $(j \times B)$ to the momentum equation; $j$ is the current density and $\mathrm{B}$ is the magnetic field. Two further equations are required: an equation for current continuity $\nabla \cdot \mathrm{j}=-\nabla \cdot(\sigma \nabla \varphi)=0$, where $\sigma$ is the electrical conductivity and $\varphi$ is the electric potential, and an expression for the magnetic field $\mathrm{B}=\nabla \times \mathrm{A}$, where the magnetic vector potential $\mathrm{A}$ is given by $\nabla^{2} \mathrm{~A}=$ 
$-\mu_{0} \mathrm{j}, \mu_{0}$ being the permittivity of free space. The effects of the sheaths are simplified by using a mesh size of $0.1 \mathrm{~mm}$ at the electrodes, as recommended by Lowke and Tanaka [23]. The pressure is equal to atmospheric pressure.

The configuration of the model and the distribution of the iron vapour mass source are shown in figure 1. The computational domain includes the contact tube $\mathrm{BQRC}$, the wire $\mathrm{ANOPB}$, the gas nozzle DEFG, the cathodic workpiece JKLM and the arc region. The arc region is the entire fluid domain, since we do not model droplet formation or flow in the weld pool. The diameter of the wire is $1.2 \mathrm{~mm}$ and the length of wire that sticks out beyond the contact tube and the arc length are each $5 \mathrm{~mm}$. We define an argon fraction of $100 \%$ at the shielding gas inlet CD and at the opening GHIJ. The shielding gas inflow rate is $12 \mathrm{l} / \mathrm{min}$. A boundary mass source of iron vapour at $3023 \mathrm{~K}$, distributed as shown in figure 1, was included at the lower side of the wire to simulate the vaporization of the wire anode. The total mass flow of iron vapour is determined relative to the wire feed rate, which is chosen as $10 \mathrm{~m} / \mathrm{min}$.

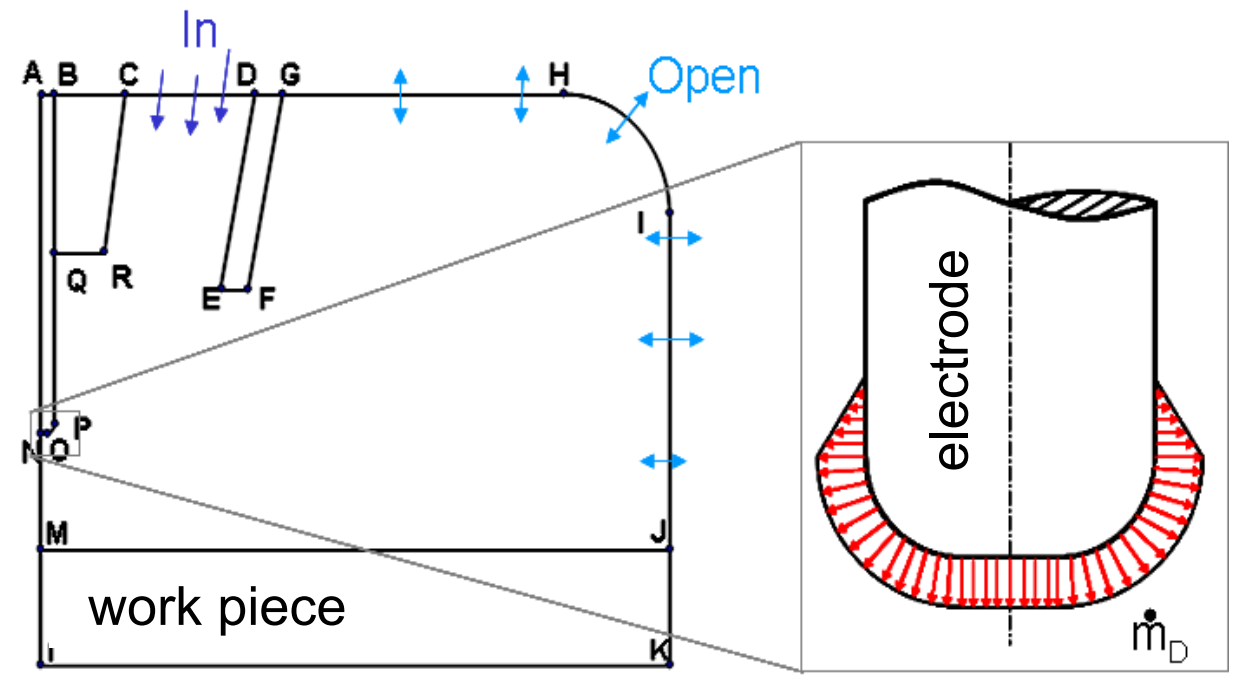

Fig. 1 Configuration of the computational domain (left) and the iron vapour mass source (right)

The plasma is assumed to be in local thermodynamic equilibrium (LTE), as is usual for models of welding arcs [20]. The thermodynamic properties were calculated for a chemical equilibrium composition, obtained using minimization of the Gibbs energy. The following species were considered: $\mathrm{Ar} \mathrm{Ar}^{+}, \mathrm{Ar}^{2+}, \mathrm{Ar}^{3+}$, $\mathrm{Ar}^{4+}, \mathrm{Fe}, \mathrm{Fe}^{+}, \mathrm{Fe}^{2+}, \mathrm{Fe}^{3+}, \mathrm{Fe}^{4+}$ and $\mathrm{e}^{-}$. The thermodynamic properties of the species were calculated using the atomic lines listed by Moore [24,25]. The transport properties, including the combined diffusion coefficients, were calculated using the Chapman-Enskog method for a temperature range of $300-30000 \mathrm{~K}[19,26]$. The required collision integrals for interactions between argon species were calculated using the methods given by Murphy and Arundell [26]. The collision integrals for $\mathrm{Fe}-\mathrm{Fe}$ interactions were obtained using the LennardJones $(12,6)$ potential, those for $\mathrm{Ar}-\mathrm{Fe}$ by averaging the $\mathrm{Ar}-\mathrm{Ar}$ and $\mathrm{Fe}-\mathrm{Fe}$ collision integrals, those for $\mathrm{Ar}-$ $\mathrm{Fe}^{+}$and $\mathrm{Fe}-\mathrm{Ar}^{+}$interactions using the polarization potential, and for those for $\mathrm{Fe}-\mathrm{Fe}^{+}$interactions using a combination of the charge exchange parameters determined from the work of Rapp and Francis [27] and the polarization potential. All collision integrals for interactions between charged species were determined using the shielded Coulomb potential. Relevant details and references are given in [26]. The $\mathrm{e}^{-}-\mathrm{Fe}$ collision integrals were determined by integrating the momentum transfer cross-section, which was obtained using the effective radius approximation for low collision energies, and the classical approximations for high collision energies [28].

The influence of the addition of iron vapour to argon on the molar weight, specific heat at constant pressure, viscosity, and the thermal and electrical conductivity is shown in Fig. 2. The addition of just $1 \%$ iron vapour has a very significant effect on the electrical conductivity at temperatures up to around $12000 \mathrm{~K}$. This is because iron atoms ionize at a much lower temperature than argon atoms. All the other properties are only weakly affected for $1 \%$ iron vapour, although changes become significant for $25 \%$ iron vapour. 

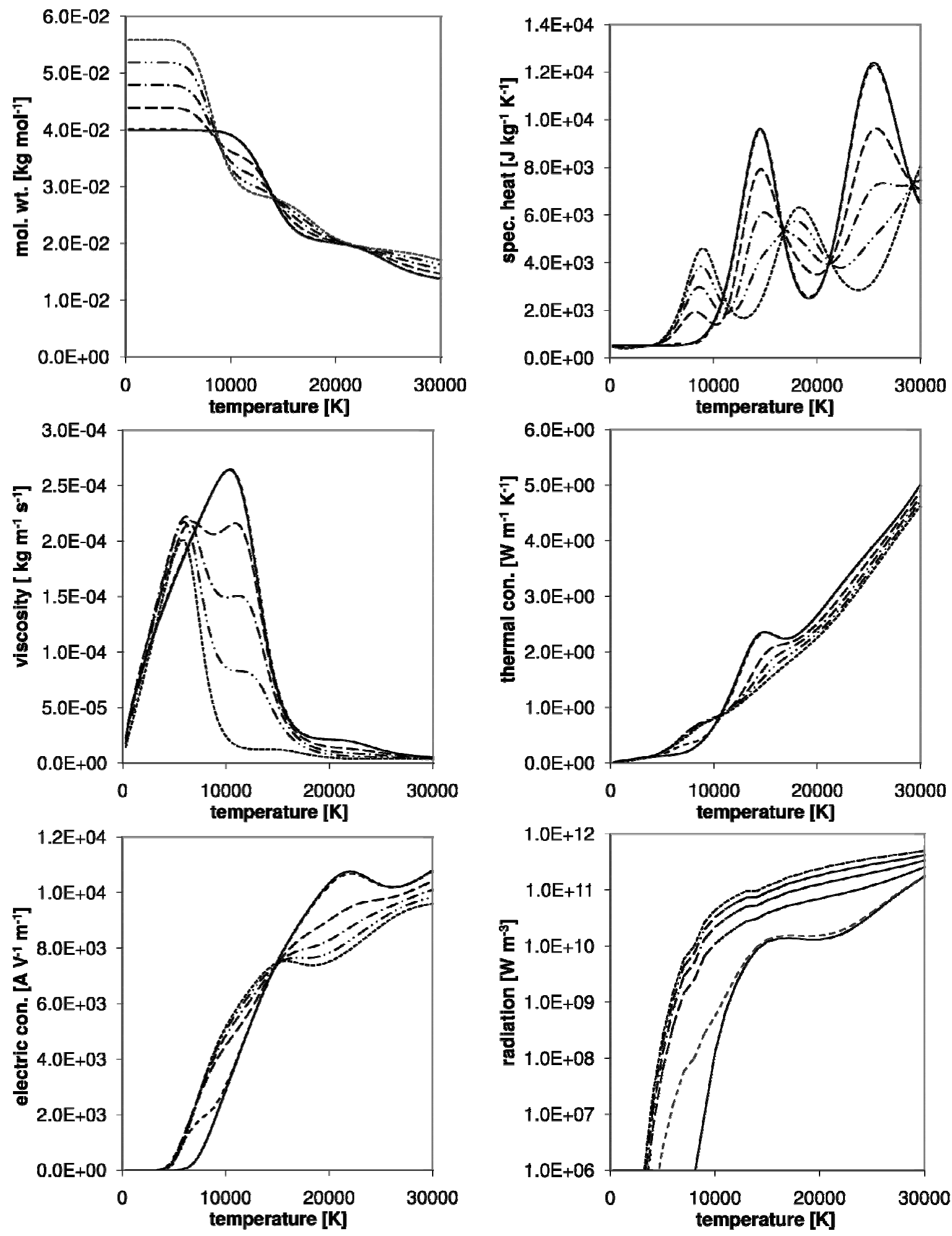

Fig. 2 Influence of iron vapour mole percentage on the average molecular weight, specific heat, viscosity, thermal conductivity, electrical conductivity and net radiative emission coefficient of mixtures of argon and iron vapour: $-0 \% \mathrm{Fe},---1 \% \mathrm{Fe}---25 \% \mathrm{Fe},-\cdot-\cdot 50 \% \mathrm{Fe},-\cdot \cdot-\cdot 75 \% \mathrm{Fe}$, ….... $100 \% \mathrm{Fe}$.

Radiation is treated using the net emission coefficient (NEC) model. 'Net' means the difference between emitted and absorbed radiation defined for a sphere with a uniform temperature. This simple radiation model allows accurate determination of the energy loss due to the radiation emission in the hottest arc regions, although it neglects the radiation transport and absorption in the colder gas [29]. Net emission coefficients have been calculated by Menart and Malik [30], Aubrecht [31] and Cram [32]. The coefficients are given as function of plasma temperature and pressure, for certain sphere radii. A 
selection of the data is shown in figure 3. The datasets of Aubrecht and Menart and Malik are in a good agreement. The values of Cram exceed both, especially for temperatures above $15000 \mathrm{~K}$. The values for a $1 \mathrm{~mm}$ sphere are almost an order of a magnitude lower than the values for $0 \mathrm{~mm}$ diameter, which neglect absorption. This is because of the large ultraviolet component, which is strongly self-absorbed. For our standard calculations, we have used the $1 \mathrm{~mm}$ sphere data of Menart and Malik, since we also assumed a $1 \mathrm{~mm}$ sphere for the NEC of argon [34], and since this represents approximately the size of the high temperature region. For mixtures of argon and iron vapour, we calculate the net emission coefficient as a mole-fraction weighted average, as recommended by Cressault et al [33]. Results are shown in figure 2. Clearly even a small amount of iron vapour greatly increases the net emission coefficient.

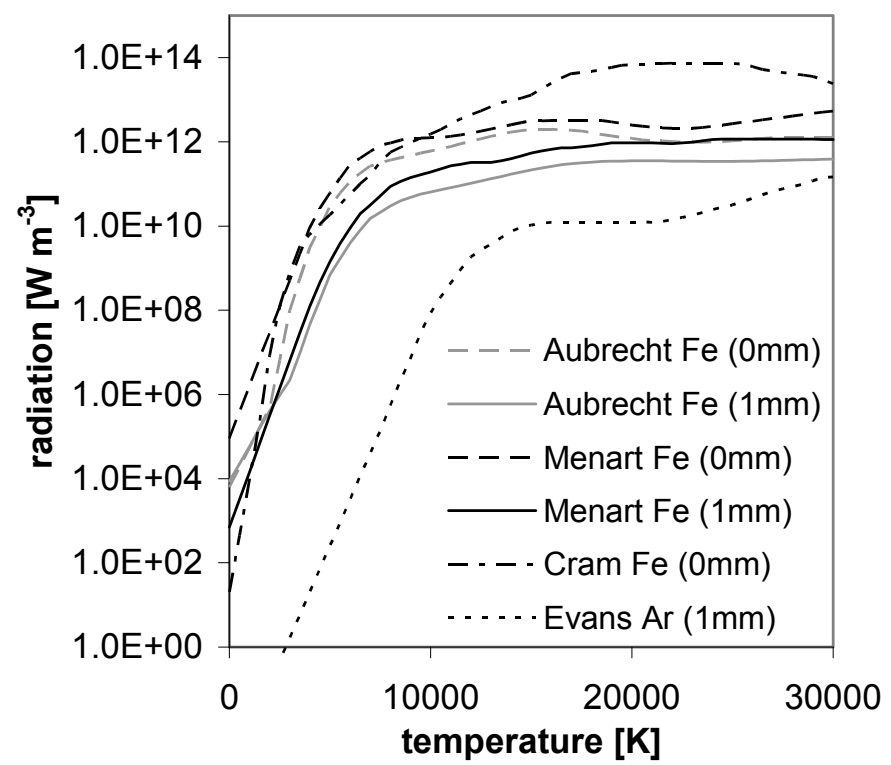

Fig. 3 Different values of net emission coefficients or iron vapour calculated by Aubrecht [31], Menart and Malik [30] and Cram [32] and the argon values of Evans and Tankin [34] for comparison. Results are given for emission without absorption $(0 \mathrm{~mm})$ and for a $1 \mathrm{~mm}$ radius absorbing sphere.

The model implements mixing of argon and metal vapour due to turbulence and diffusion effects. Turbulence was included using the shear stress transport turbulence model [35]. This approach combines the $\mathrm{K}-\omega$ model in regions near walls and the $\mathrm{K}-\varepsilon$ model in regions away from the walls. It has been rated the most accurate turbulence model (compared with two other two-equation models and a one-equation model) for a wide range of flows [36]. It was found that the inclusion of turbulence in fact has a negligible influence on the predicted arc properties. In particular, the turbulent diffusion coefficient, also known as eddy diffusion, was negligible compared with the ordinary diffusion coefficient, calculated as described below. The turbulent diffusion coefficient $D_{t}$ is given by $D_{t}=\eta_{t} /(\rho S c)$, where $S c$ is the turbulent Schmidt number, set to 0.9 , and $\eta_{\mathrm{t}}=\rho \mathrm{K} / \omega$ is the turbulent viscosity (eddy viscosity). The spatial distributions of the turbulent kinetic energy $\mathrm{K}$ and the turbulent frequency $\omega$ are determined by solving the equations of the turbulence model.

The combined diffusion coefficient model [21,37] is used to treat diffusion of metal vapour relative to argon. It is based on a conservation equation for iron vapour mass fraction $y_{F e}$ (defined as the sum of the mass fractions of the component species $\mathrm{Fe}, \mathrm{Fe}^{+}, \mathrm{Fe}^{2+}, \mathrm{Fe}^{3+}$ and $\mathrm{Fe}^{4+}$ ):

$$
\frac{\partial\left(\rho y_{F e}\right)}{\partial t}+\operatorname{div}\left(\rho \vec{u} y_{F e}+\vec{J}_{F e}\right)=0
$$

where $\rho$ is the mass density, $u$ is the flow velocity, and the iron vapour diffusion mass flux is

$$
\vec{J}_{F e}=\frac{n^{2}}{\rho} \bar{m}_{F e} \bar{m}_{A r}\left(D_{F e A r}^{x} \operatorname{grad} x_{A r}+D_{F e A r}^{p} \operatorname{grad} \ln p_{t o t}+D_{F e A r}^{E} \vec{E}\right)-D_{F e A r}^{T} \operatorname{grad} \ln T
$$

The terms describe diffusion due to the gradient in the mole fraction of argon, due to the gradient in the total pressure, due to the electric field of the arc and due to the temperature gradient, respectively. The $m_{\mathrm{Fe}}$ and $m_{\mathrm{Ar}}$ are respectively the average molar masses of the argon and iron vapour heavy species and $n$ is the number 
density. The $D_{F e A r}^{I}$ are the combined diffusion coefficients, respectively due to mole fraction gradients, gradients in the total pressure, the arc electric field, and the temperature gradient. They are shown in figure 4, and are all clearly strongly affected by the proportion of iron vapour present.
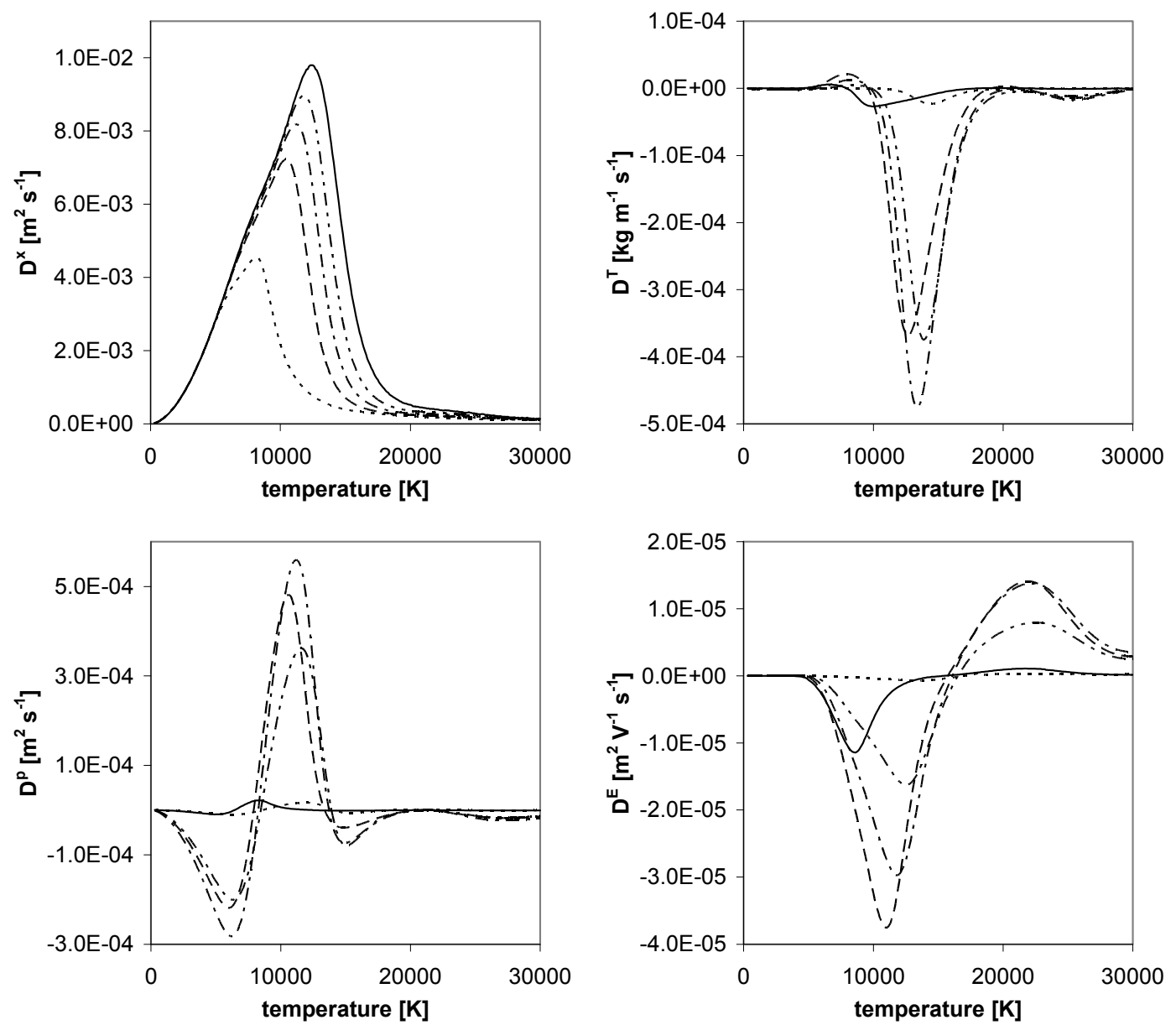

Fig. 4 Combined diffusion coefficients of iron vapour in argon for different iron vapour mole percentages:

$$
1 \% \mathrm{Fe},---25 \% \mathrm{Fe},-\cdot-\cdot 50 \% \mathrm{Fe},-\cdot \cdot-\cdot 75 \% \mathrm{Fe}, \cdots \cdots \cdots . .19 \% \mathrm{Fe}
$$

\section{RESULTS}

Figure 5 shows predicted temperature, iron vapour mass fraction and velocity distributions for a $250 \mathrm{~A}$ arc and a vaporization rate of $1 \%$ relative to the wire feed rate. For the wire feed rate of $10 \mathrm{~m} / \mathrm{min}$ and wire diameter of $1.2 \mathrm{~mm}$, this corresponds to $0.015 \mathrm{~g} / \mathrm{s}$. The highest arc temperature of $18000 \mathrm{~K}$ is predicted on the centre line, directly below the wire. Closer to the workpiece, a local minimum in the radial temperature distribution is predicted at the centre of the arc. At a height of $1.5 \mathrm{~mm}$ above the workpiece, the central temperature is $10000 \mathrm{~K}$ whereas the highest temperature of $12500 \mathrm{~K}$ occurs off axis. These results are in qualitative agreement with those of the measurements referred to in section 1 $[10,11,12]$, but differ strongly from those predicted by previous models of GMAW, which neglect the effects of metal vapour $[4,5,6]$. 


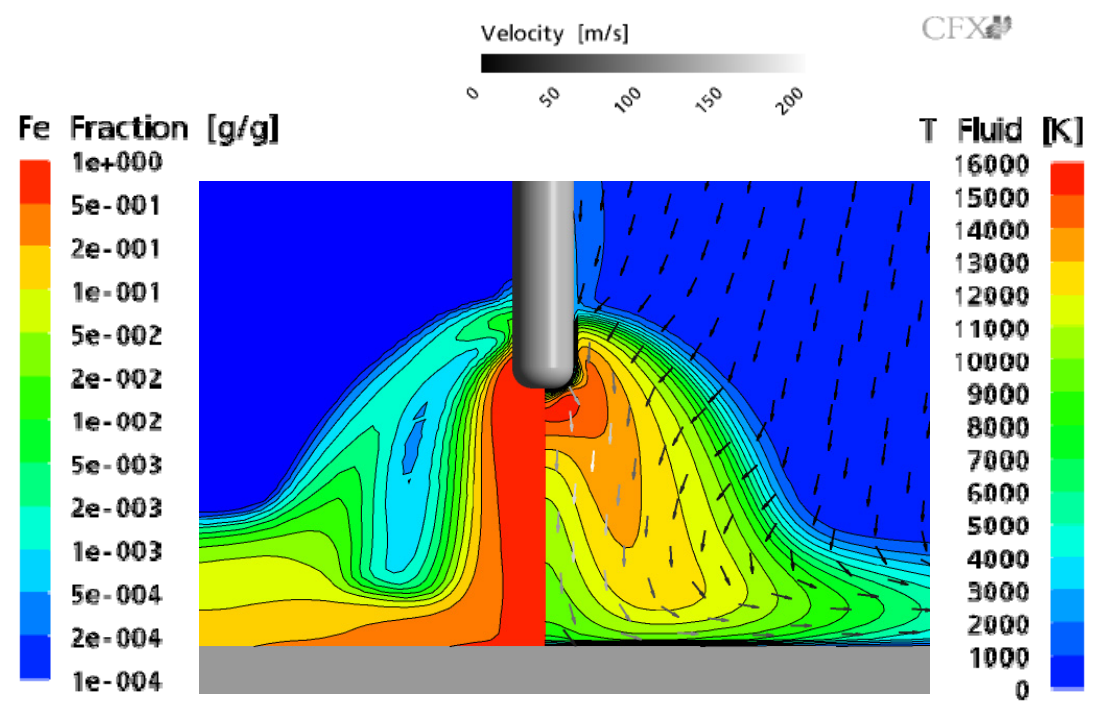

Fig. 5 Calculated values of temperature (right), iron vapour mass fraction (left), and the gas flow (vectors) in a $250 \mathrm{~A}$ arc with a vaporization rate of $1 \%$ relative to the $10 \mathrm{~m} / \mathrm{min}$ wire feed rate.

The calculated mass fraction of the iron vapour shows an accumulation in the arc core. This arises from the position of the iron vapour boundary source at the tip of the wire, and the strong downward plasma flow, driven by the magnetic pinch force. Another accumulation is visible at the arc edge between 2000 and $5000 \mathrm{~K}$. Demixing effects lead to low mass fractions of iron vapour $\left(y_{F e}<1\right.$.E-3) between these two accumulations, as discussed below.

The calculated mass fraction distribution is consistent with the observed sharp optical separation of the arc core, which mainly dominated by the metal vapour and the outer arc regions. Steep gradients are predicted at the border of the arc core. The vapour accumulation in the outer regions is correlated with the well-known (especially for GMAW with magnesium-alloy aluminium wire) optically-bright arc fringes. The highest temperatures and current densities occur at the boundary of the arc core.

Results given previously [22] showed that the separation between metal vapour in the central region and argon in the edge regions is stronger for higher arc currents. This is because the magnetic pinch force, which drives the downward convective flow from the wire electrode, increases with arc current. The central temperature minimum extends further downwards for higher currents, and is very weak for a current of $100 \mathrm{~A}$.

Analyses of the sensitivity of the four driving forces of diffusion demonstrated that the temperature and the mole fraction gradients are the strongest sources of demixing. The effects of the electric field and the pressure gradient were very small and could be neglected. Diffusion due to mole fraction gradients leads to a flux of the chemical element with the lower ionization energy from higher- to lowertemperature regions. Diffusion due to temperature gradients drives a flux of the lighter chemical element in the same direction [20,21]. In both cases, it is the iron vapour that will flow from higher- to lowertemperature regions. The off-centre radial maximum of the temperature leads to iron vapour diffusion fluxes both radially outwards and inwards, leading to the minimum in iron vapour concentration at a similar radius. However, a calculation performed neglecting the effects of demixing demonstrates that the high axial plasma flow velocity is the primary reason for the high iron vapour concentration in the arc core and the low fraction in the arc fringes.

We have previously investigated the relative importance of electric conductivity, strong radiative emission of metal vapour and the direct cooling of the arc due to vapour's relatively-low initial temperature of $3000 \mathrm{~K}$ [22]. Calculations were performed with the iron vapour replaced by the same mass flux of argon at $3000 \mathrm{~K}$, and with the same mass flux of an imaginary vapour with argon properties, but with the radiative emission coefficient or the electrical conductivity of iron vapour. Results are shown in figure 6. It was thereby demonstrated that the main mechanism for the decrease in temperature near the arc axis is the strong radiative emission of iron vapour. The direct cooling caused by the influx of vapour is relatively small, accounting for a decrease in the central temperature of only about $1000 \mathrm{~K}$. The influence of the much higher electrical conductivity of iron vapour is very small, too. The influence 
of all other thermophysical properties on the central temperature was also tested and found to be similarly small. Finally, it was noted that the power required to vaporize the iron is negligible. It is less than $5 \%$ compared with the total radiated power.
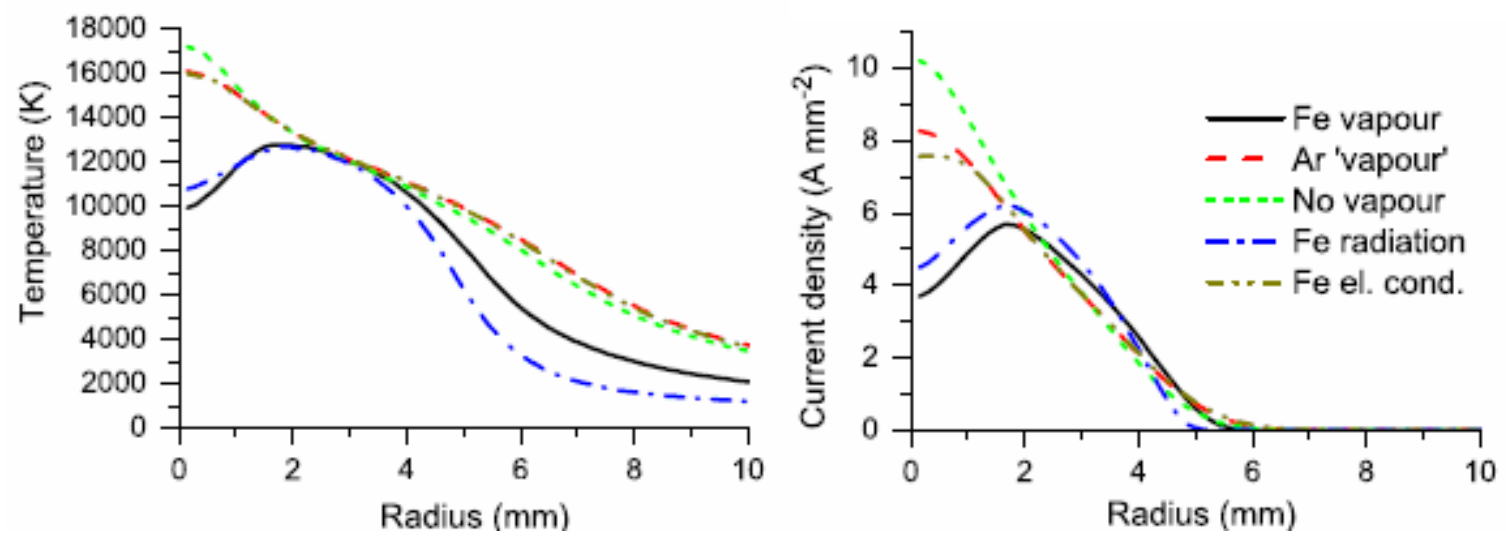

Fig. 6 Influence on the temperature and current density of iron vapour, the same mass flux of argon and the same mass flux of imaginary gases with the properties of argon except for the radiative emission coefficient or the electrical conductivity of iron vapour. Results are for a position $1.5 \mathrm{~mm}$ above the workpiece in a $250 \mathrm{~A}$ arc [22].

\section{INFLUENCE OF NEC DATA IN MODELLING METAL VAPOUR RADIATION}

As noted in section 3, the main mechanism for the decrease in temperature near the arc axis is the strong radiative emission from the iron vapour. We also showed (see figure 3 ) that there are significant differences between the NEC data calculated by different researchers, and also according to the absorbing sphere radius. To investigate how important these differences are, we have performed calculations for different sets of NEC values. The results are shown in figure 7.

We find that the results for each set of NEC values are in general agreement. In particular, the radial temperature distribution shows an off-axis maximum for all the sets. However, there are major differences in the temperature values on the arc axis, especially directly below the wire. Calculations for the NEC values with a $1 \mathrm{~mm}$ absorbing sphere give a maximum temperature directly below the wire of about $16000 \mathrm{~K}$. The temperature on the arc centre line decreases gradually in the direction of the workpiece.

In contrast, the $0 \mathrm{~mm}$ NEC values give central arc temperatures below $7000 \mathrm{~K}$ and the maximum arc temperatures always occur off axis. The NEC values of Cram [32] are higher than the others, particularly for temperatures above $15000 \mathrm{~K}$. However, since the temperature of the arc core is relatively low, the arc temperature, current density and axial velocity distributions are very similar to those obtained using the $0 \mathrm{~mm}$ NEC values of Menart and Malik [30] and Aubrecht [31].

As a consequence of the much lower central arc temperature for the $0 \mathrm{~mm}$ NEC values, the model predicts a near-zero current density in the arc core and on the lower side of the wire. This means the arc attachment is situated towards the sides of the wire. As a consequence, the current density and therefore the magnetic pinch force is lower, so the velocity is smaller. It is likely that the altered attachment will also affect the heat transfer to the wire, and therefore the rate and distribution of the vaporization. Unfortunately due to the simple sheath model we use, and the assumption of constant evaporation rate, we cannot model these effects. Nevertheless, they are of academic interest only, since the $1 \mathrm{~mm}$ NEC values are more realistic, since in reality there will be significant self-absorption of the emitted radiation. 


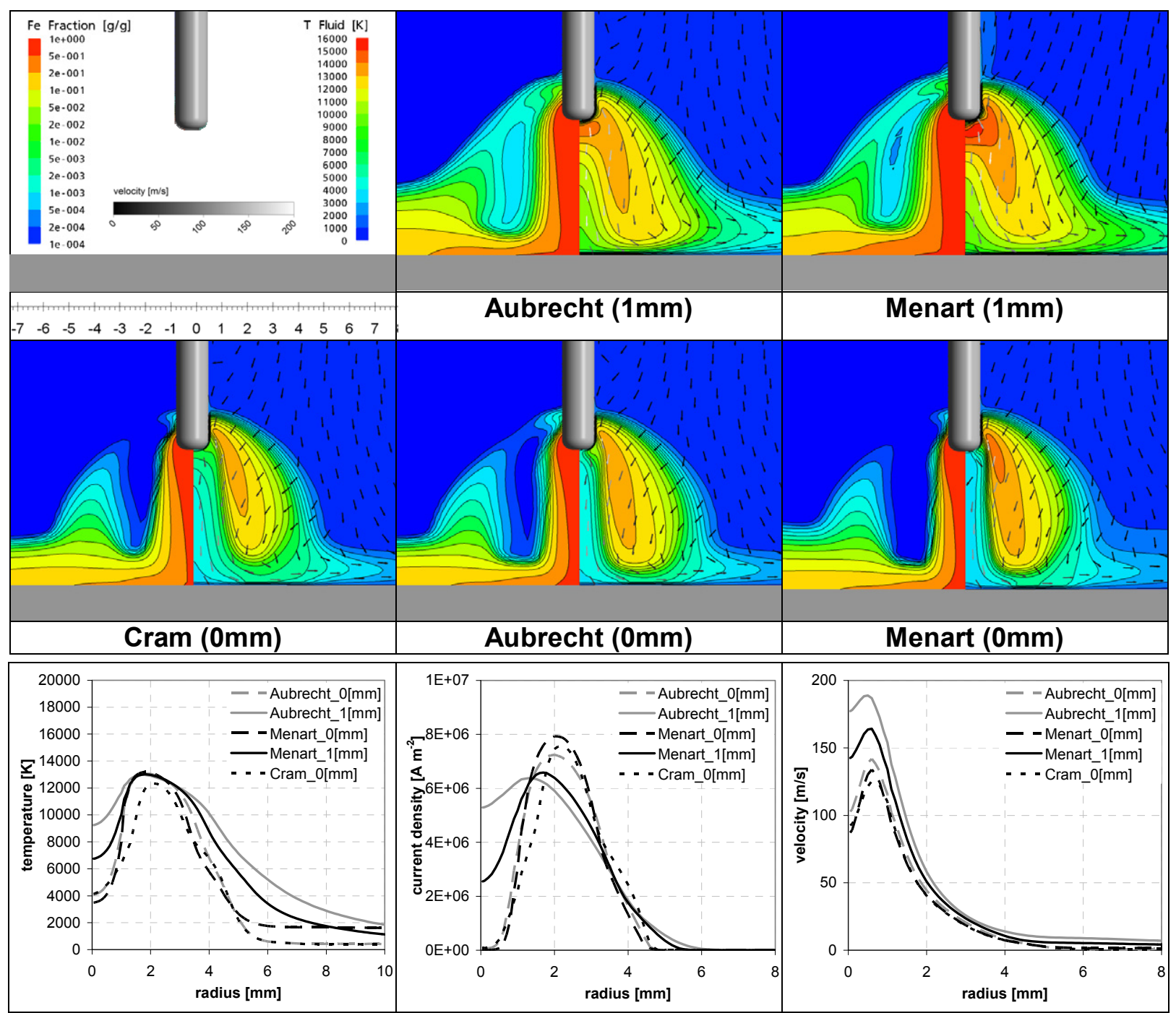

Fig. 7 Influence of different net emission coefficient data in a $250 \mathrm{~A}$ arc with $1 \%$ vaporization rate relative to the wire feed rate of $10 \mathrm{~m} / \mathrm{min}$ (top: temperature and flow velocity vectors (right) and metal vapour mass fraction (left) and bottom: radial distributions of temperature, current density and velocity at a position $1.5 \mathrm{~mm}$ above the workpiece).

\section{INFLUENCE OF VAPORIZATION RATE}

As discussed in section 3, the influence of the welding current (100 to $400 \mathrm{~A}$ ) on arc temperatures and flow field has been examined previously [22]. GMAW at a current of $400 \mathrm{~A}$ with argon is characterized by the spray mode of droplet transfer; this means that the wire melts so that its tip forms a cone of liquid and a large number of small detaching droplets is produced. Observations of a spray mode arc at these parameters show a differently-shaped metal vapour distribution in the arc core; the strongly-radiating metal vapour region looks more like a cone than a cylinder. Numerical analyses demonstrate that the shape of the metal-vapour-dominated region is mainly affected by the vaporization rate. The calculations presented above were all done for vaporisation rates of $1 \%$ of wire feed. However, vaporization rates of $5-10 \%$ were measured for GMAW of aluminium alloys and a rate of $5 \%$ was measured for GMA brazing with copper filler [10].

Figure 8 shows the calculated metal vapour mass fraction, arc temperature and flow vectors of $250 \mathrm{~A}$ arcs depending on the vaporization rate relative to a wire feed rate of $10 \mathrm{~m} / \mathrm{min}$. For a low vaporization rate of $0.1 \%$, the model predicts a narrow metal-vapour region as well as a flow field and arc temperatures very similar to those found in TIG arcs. The influence of the metal vapour is close to negligible. Vaporization rates above about 3\% cause a dramatic change in the arc flow field and the metal vapour distribution. As can be seen in the results for the vaporization rate of $5 \%$, the region with 
the metal vapour mass fraction above 0.5 (the red region) becomes conical. A similar conical region of low temperature is formed.

The results indicate that the formation of the conical metal vapour distribution is accompanied by a reversal of the direction of plasma flow in the centre of the arc. In contrast to all previous results, the central plasma flow is directed axially from the workpiece towards the wire.

In the fringes of the arc the direction of flow is radially inward and axially downward. This outer region is characterized by the highest temperatures and a high flow velocity. Especially in the upper arc region there are high gradients of the metal vapour content between the iron vapour and argon plasma regions.
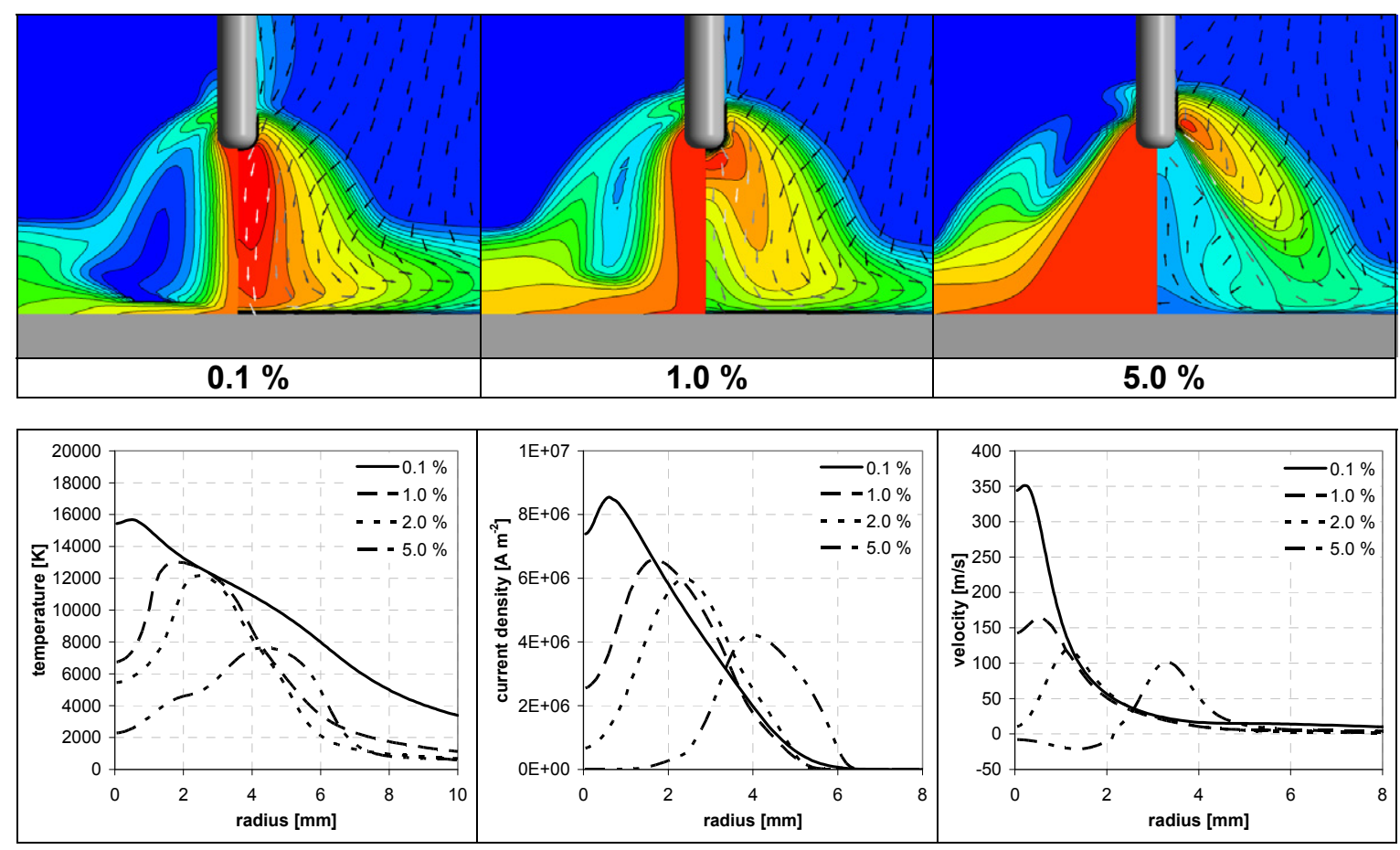

Fig. 8 Influence of the vaporization rate, relative to wire feed rate of $10 \mathrm{~m} / \mathrm{min}$, in a $250 \mathrm{~A}$ arc using the 1 mm NECs of Menart and Malik (top: the temperature distribution and flow vectors (right) and metal vapour mass fraction distribution (left), images are scaled and sized as in figure 7 and bottom: radial distributions of temperature, current density and downward velocity at a position of $1.5 \mathrm{~mm}$ above the workpiece).

The lower half of figure 8 shows the radial distributions of temperature, current density and the axial flow velocity $1.5 \mathrm{~mm}$ above the workpiece. The radial position of the maximum in temperature and current density shifts radially outwards as the vaporization rate increases. For vaporization rates above about $2 \%$, the current density in the arc core vanishes because of the low temperature. In such cases, the electric current flows through the high-temperature region between the metal vapour and argon plasma regions.

An interesting property of the arc in the case of 5\% vaporization rate is that the velocity at radii less than $2 \mathrm{~mm}$ is directed upwards. This behaviour is very unusual; it is generally found, in both measurements and simulations, that the flow velocity is downwards in free-burning arcs such as those used in GTAW and GMAW. Upwards flow can be obtained when the attachment to the lower electrode is forced to be constricted [38]; however the attachment here is diffuse. We attribute the flow reversal to the strong radiative cooling of the central regions of the arc because of the high metal vapour concentration. This decreases the electrical conductivity in this region, so the current is forced to flow at higher radii. The magnetic pinch force then drives the downward plasma flow at these higher radii. Mass continuity then leads to the upward plasma flow in the central regions 


\section{COMPARISION WITH EXPERIMENTAL RESULTS OF ZIELINSKA ET AL.}

We have mentioned three recent publications containing results of arc temperature distributions in GMAW. The results of $[10,11]$ are related to pulsed GMAW processes and aluminium or copper wires. The measurements of Zielinska et al [12] are most relevant to the calculations presented here, because they are for spray-transfer mode GMAW, which can be approximated by a steady-state calculation, and an iron wire was used. The arc temperature measurements were performed for rather academic welding parameters, with a much longer arc than used industrially. A measured arc temperature distribution was presented for spray-transfer mode GMAW with an arc current of $330 \mathrm{~A}$, a wire feed rate of $9 \mathrm{~m} / \mathrm{min}$ and argon as shielding gas. We obtained best agreement with the measured radial temperature distributions using a vaporization rate of $3 \%$ relative to the wire feed rate .

For the purposes of comparison of our numerical predictions with the experimental results of spraytransfer mode GMAW, the idealized wire tip shape and the assumption of a flat workpiece without weld pool depression are not longer suitable. Thus the geometrical boundary conditions of the partially liquid wire were determined using the high-speed video images also presented by Zielinska et al [12]. The shape of the depressed weld pool can not be extracted from these pictures, because it is obscured by the workpiece. We assumed a weld pool depression with a depth of $2 \mathrm{~mm}$ and a diameter of $7 \mathrm{~mm}$. The presence of detached droplets between wire and workpiece was neglected.

To allow a comparison between simulations and high-speed video images, the calculated distribution of the net radiative emission for an axisymmetric plasma was used to determine the intensity distribution of radiation from the arc, viewed from side on. The axisymmetric calculation gives the local radiation intensity $\operatorname{rad}(\mathrm{z}, \mathrm{r})$ where $\mathrm{z}$ is the vertical and $\mathrm{r}$ the radial position. The side-on view radiation (as recorded by the camera) $\operatorname{Rad}(\mathrm{z}, \mathrm{x})$, with horizontal distance $\mathrm{x}$ from arc axis, was calculated by an integral of the local radiation intensity over a line of sight perpendicular to axial direction $\mathrm{z}$, according to

$$
\operatorname{Rad}(\mathrm{h}, \mathrm{x})=\int \operatorname{rad}\left(\mathrm{h}, \frac{\mathrm{x}}{\cos \alpha}\right) \cdot x \cdot\left(1+\tan ^{2} \alpha\right) d \alpha
$$

Here $\alpha$ is the angle between the axial direction and the radial direction to the integration point on the line of sight.

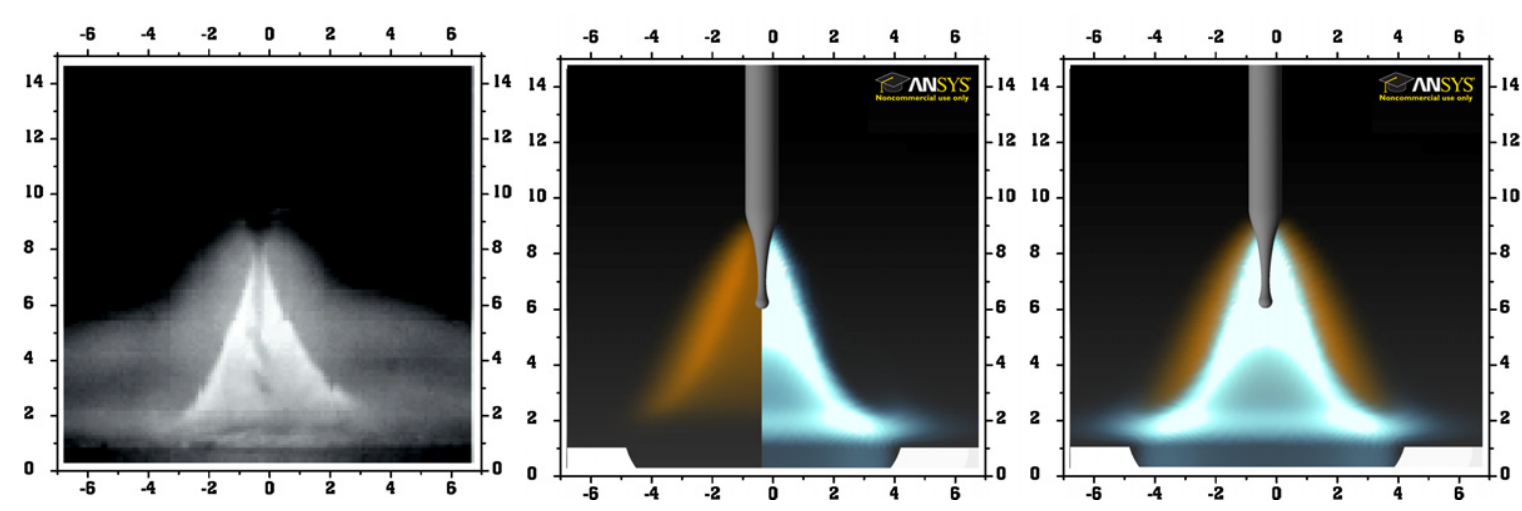

Fig. 9 Comparison of a high-speed video images (left) with reconstructions of calculated radiation intensity for spray-transfer mode GMAW with arc current of $330 \mathrm{~A}$. The middle figure shows the argon (scaled transparent to red) and iron vapour radiation (scaled transparent to blue) separately; the right-hand figure shows them combined.

Figure 9 shows a high-speed video image [12] and the calculated radiation intensity. The radiative contributions of argon and metal vapour were calculated separately; the metal vapour radiation mainly contains lines at wavelengths below $650 \mathrm{~nm}$, and is scaled transparent-to-blue, and the argon radiation mainly contains lines above $650 \mathrm{~nm}$ and is scaled transparent-to-red.

The figure demonstrates good agreement, especially for the shape of the metal vapour radiation. The highest metal vapour and argon radiation intensities were calculated at the edge of the conical arc core. There is a lower-intensity region inside the metal vapour zone of the arc in both measured and calculated figures; this is due to the much lower temperatures in the lower central region of the arc. The predicted extent of the argon radiative emission is much smaller than in the measured image. This is expected, since it has been shown that absorption and reemission of radiation by the cool gas surrounding argon 
arcs leads to radiative emission from regions up to $10 \mathrm{~mm}$ or more from the arc core $[39,40]$. Such radiative transfer effects are of course not taken into account in the NEC approach, and therefore cannot be reproduced by the model.

The left-hand side of figure 10 shows a quantitative comparison between the measured and numerically-predicted radial temperature distributions at different heights above the workpiece. The distributions of the iron vapour content and temperature as well as the flow velocity vectors are shown on the right-hand side. The numerical predictions are in reasonable agreement with the measurements (note that the temperature scale starts at $6000 \mathrm{~K}$, which exaggerates the discrepancies). In particular, the radial positions at which the maximum temperatures occur agree closely. The discrepancies in temperature are around $2000 \mathrm{~K}$, with the calculated temperatures generally exceeding the measured temperatures, especially in the outer arc regions.
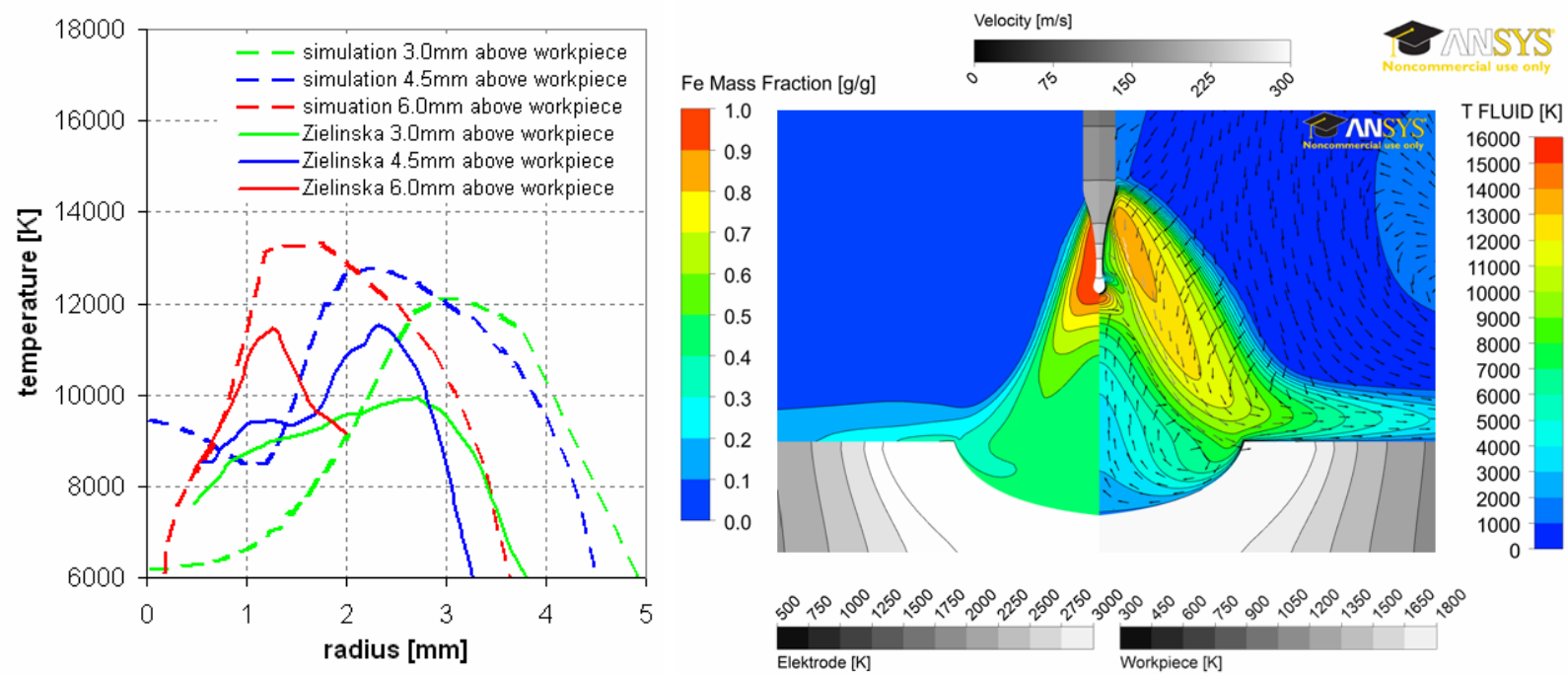

Fig. 10 Comparison between predicted and measured radial temperature distributions at different heights above the workpiece (left), and calculated metal vapour mass fraction and temperature distributions and flow velocity vectors (right) of a spray-transfer mode GMAW process for an arc current of $330 \mathrm{~A}$.

We emphasize that there are many uncertainties inherent in the comparison. In particular, the rate of vaporization of the wire, the distribution of the metal vapour source at the edge of the wire, and the shape of the weld pool depression are not known and are estimated values are used in the model. Further, we have not taken into account the influence of droplets falling through the arc. Nevertheless, the reasonable agreement between the predictions and the measurements suggests that the most important physical processes are adequately taken into account in the model. In particular, the flow reversal found for high vaporization rates in section 5 is again present. Our simulations indicate that the conical region of high metal vapour concentration in the arc centre is always associated with the flow reversal. As discussed in section 5 , this is a conequence of the strong radiative cooling in the central region of the arc, and the consequent effects on the current density and flow distributions. The fact that we are able to predict the observed temperature profile and the radiative emission distribution is evidence that the flow reversal is indeed occurring.

\section{CONCLUSIONS}

An MHD model of the GMAW process has been used for numerical studies of the influence of iron vapour on the arc temperature and the current transfer. An iron vapour mass source was defined at the lower side of the wire. The effects of turbulent mixing and laminar diffusion and demixing have been taken into account. The model predicts a central minimum in the radial distributions of temperature and 
current density, which is caused by a high concentration of metal vapour in the arc core and its high radiative emission.

Since the radiative emission is critical in determining the arc properties, and since published net radiation emission coefficients differ by a large factor, it was important to investigate the sensititivity of the model's predictions to the dataset used. We found that simulations performed for the different datasets gave qualitatively similar results. However, net emission coefficients calculated without taking into account self-absorption gave much lower temperatures and current densities near the arc centre line. The strong ultraviolet component of the radiation from metal vapour means that this is unrealistic, and it is important to consider the presence of an absorbing sphere.

The rate of vaporization of the wire has a strong influence on the arc temperature and current density distributions, affecting both the maximum and minimum temperatures and the position of the minimum. The model also predicts a significant influence on the arc flow field. For high vaporization rates of 3-5\% or more relative to the wire feed rate, a reversal of the plasma flow direction for the inner arc region was predicted. Downward flow occurs in the outer regions of the arc, and an upward flow occurs in the central regions. Such a flow reversal has not been previously observed in welding arcs. However, it appears to be associated with a change in the shape of metal vapour distribution; the shape of the central region with high-metal vapour concentration was predicted to change from cylindrical at low vaporization rates to conical at high vaporization rates.

While there is no direct measurement of the flow reversal, its existence has been given indirect support through the comparison of our modelling results with the arc temperature measurements and high-speed video images of Zielinska et al [12]. The images showed a conical metal vapour region, in agreement with the predictions of our model. Further, good agreement was obtained with the position of the offcentre temperature maximum and reasonable agreement with the temperature values. These results suggest that our simulations are taking into account the main physical processes, and therefore that the prediction of the inner flow reversal is realistic.

\section{ACKNOWLEDGEMENTS}

This work was partially supported by DFG (FK: FU 307/5-1), which is gratefully acknowledged. Many thanks to Dr. J. J. Lowke of CSIRO Materials Science and Engineering, Australia, Prof. M. Tanaka of Joining and Welding Research Institute, Osaka University, Japan and Dr. D. Uhrlandt of Leibniz-Institut für Plasmaforschung und Technologie, Germany for the discussions of these results.

\section{REFERENCES}

[1] D. RADAJ: Schweißprozesssimulation: Grundlagen und Anwendung. Verlag für Schweißen und verwandte Verfahren DVS-Verlag GmbH, Düsseldorf 1999

[2] C. HIRT, B. NichOLS: 'Volume of fluid method for the dynamics of free boundaries', J. Comput. Phys., Vol. 39, 1981.

[3] Y. WANG, Q. SHI, H.L. TSAI: Modeling of the effects of surface-active elements on flow patterns and weld penetration. Metall. Trans., Vol. 32B, pp. 145-61, 2001

[4] J. HAIDAR: An analysis of the formation of metal droplets in arc welding, J. Phys. D: Appl. Phys., Vol. 31, pp. 1233-44, 1998.

[5] J. HU, H.L. TSAI: Heat and mass transfer in gas metal arc welding. Part I: The arc, Int. J. Heat Mass Transfer, Vol. 50, pp. 833-46, 2007.

[6] J. Hu, H.L. TsAI: ,Heat and mass transfer in gas metal arc welding. Part II: The metal', Int. J. Heat Mass Transfer, Vol. 50, pp. 808-20, 2007. 
[7] A. SPILle-KoHOFF: ,Numerische Simulation des ChopArc-Schweißprozesses' final research report: ChopArc, Fraunhofer IRB Verlag, 2005.

[8] J.J. LOWKE, R. MORROW, J. HAIDAR: ,A simplified unified theory of arcs and their electrodes', $J$. Phys. D: Appl. Phys., Vol. 30, pp. 2033-42, 1997.

[9] L. SANSONNENS, J. HAIDAR, J.J. LOWKE: ,Prediction of properties of free burning arcs including effects of ambipolar diffusion' J. Phys. D: Appl. Phys., Vol. 33, pp. 148-57, 2000.

[10] E. METZKE, H. SCHÖPP: 'Spektralanalyse Metall-Lichtbogenplasma', ABSCHLUSSBERICHT CHOPARC, FRAUNHOFER IRB VERLAG, 2005.

[11] S. F. GOECKE: 'Auswirkungen von Aktivgaszumischungen im vpm-Bereich zu Argon auf das MIGImpulsschweißen von Aluminium', PhD thesis, TU BERLIN, 2004.

[12] Zielińska S, Musioł K, Dzierżęga K, Pellerin S, Valensi F, de Izarra C and Briand F 2007 Plasma Sources Sci. Technol. 16 832-8

[13] F. BRIAND ET AL.: 'Experimental investigations of the arc in MIG-MAG welding', $S G$ 212, IIW Doc.212-1123-08, Proc. of IIW Meeting, 2008.

[14] Murphy A B, Tanaka M, Yamamoto K, Tashiro S, Sato T and Lowke J J 2009 Modelling of thermal plasmas for arc welding: the role of shielding gas properties and of metal vapourJ. Phys. D: Appl. Phys. 42194006

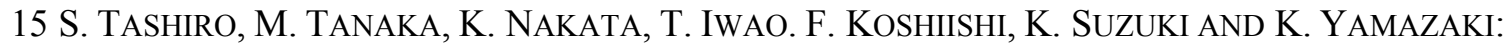
'Plasma properties of helium gas tungsten arc with metal vapour', Sci. Technol. Weld. Join., Vol. 12, pp. 202-207, 2007.

[16] K. YAmAmoto, M. TANAKa, S. TASHiRO, K. NAKATA, E. YAmamoto, K. YAMAZAKI, K. SUZUKi, A.B. MURPHY AND J.J. LOWKE: 'Numerical simulation of diffusion of multiple metal vapors in a TIG arc plasma for welding of stainless steel', SG 212, IIW Doc.212-1121-08, Proc. of IIW Meeting, 2008.

[17] K. Yamamoto, M. TANAKa, S. TAShiRo, K. NaKata, K. YAmaZaKi, E. Yamamoto, K. SuzUKi AND A. B. MURPHY: 'Metal vapour behaviour in thermal plasma of gas tungsten arcs during welding', Sci. Technol. Weld. Join., Vol. 13, pp. 566-72, 2008.

[18] Lago F, Gonzalez J J and Gleizes A 2003 A numerical modelling of an electric arc and its interaction with the anode: Part I The two dimensional model J. Phys. D: Appl. Phys. 37 883-97

[19] Murphy A B 1996 A comparison of treatments of diffusion in thermal plasmas J. Phys. D: Appl. Phys. 29 1922-32

[20] Murphy A B 1997 Demixing in free-burning arcs Phys. Rev. E. 55 7473-94

[21] Murphy A B 2001 Thermal plasmas in gas mixtures J. Phys. D: Appl. Phys. 34 R151-73

[22] Schnick M, Füssel U, Hertel M, Spille-Kohoff A and Murphy A B 2010 Metal vapour causes a central minimum in arc temperature in gas-metal arc welding through increased radiative emission $J$. Phys. D: Appl. Phys. 43022001

[23]Lowke J J and Tanaka M 2006 'LTE-diffusion' approximation for arc calculations J. Phys. D: Appl. Phys.39 3634-43. 
[24] Moore C E 1949 Atomic Energy Levels Circular 467, Vol 1 (Washington DC: US National Bureau of Standards)

[25] Moore C E 1952 Atomic Energy Levels Circular 467, Vol 2 (Washington DC: US National Bureau of Standards)

[26] Murphy A B and Arundell C J 1994 Transport coefficients of argon, nitrogen, oxygen, argonnitrogen, and argon-oxygen plasmas Plasma Chem. Plasma. Process. 14 451-90

[27] Rapp D and Francis W E 1962 Charge exchange between gaseous ions and atoms J. Chem. Phys. 37 $2631-45$

[28] Cherny G G, Losev S A, Macheret S O and Potapkin B 2002 Physical and Chemical Processes in Gas Dynamics: Cross Sections and Rate Constants Vol 1 (Reston, USA: AIAA)

[29] Murphy A B, Boulos M I, Colombo V, Fauchais P, Ghedini E, Gleizes A, Mostaghimi J, Proulx P and Schram D C 2008 Advanced thermal plasma modelling High Temp. Mater. Process. 12 255-336

[30] Menart J and Malik S 2002 Net emission coefficients for argon-iron thermal plasmas'J. Phys. D: Appl. Phys. 35 867-74

[31] Aubrecht V 2010 J Phys D: Appl. Phys. this issue

[32] Cram L E 1985 Statistical evaluation of radiative power losses from thermal plasmas due to spectral lines J. Phys. D: Appl. Phys. 18 401-11

[33] Cressault Y, Teulet P and Gleizes A 2008 Thermal plasma properties in gas or gas-vapour mixtures Proc. 17th Int. Conf. on Gas Discharges and their Applications (Cardiff, 7-12 September 2008) ed. J E Jones (Cardiff: GD2008 Local Organizing Committee) pp 149-52

[34] Evans D L and Tankin R S Measurement of emission and absorption of radiation by an argon plasma1967 Phys. Fluids 10 1137-44

[35] Menter F R 1994 Two-equation eddy-viscosity turbulence models for engineering epplications AIAA J. 32 1598-605

[36] Bardina J E, Huang P G and Coakley T J 1997 Turbulence Modeling Validation, Testing, and Development NASA Technical Memorandum 110446 (Moffett Field, CA: NASA Ames Research Center)

[37] Murphy A B 2003 Diffusion in equilibrium mixtures of ionized gas Phys. Rev. E 48 3594-603

[38] Heberlein J, Mentel J and Pfender E 2010 The anode region of electric arcs: a survey J. Phys. D: Appl. Phys. 43023001

[39] Farmer A J D and Haddad G N 1988 Rayleigh scattering measurements in a free-burning argon arc J. Phys. D: Appl. Phys. 21 426-31

[40] Murphy A B, Farmer A J D and Haidar J 1992 Laser-scattering measurements of temperature profiles of a free-burning arc Appl. Phys. Lett. 60 1304-6 